\title{
Selective detection of aromatic nitrophenols by a MOF-based fluorescent sensor
}

Xiaodie Zhang, ${ }^{\dagger}$ Guojian Ren, ${ }^{* \dagger}$ Meiling Li, ${ }^{\dagger}$ Weiting Yang, ${ }^{* \dagger}$ Qinhe Pan ${ }^{* \dagger}$

$\xi$

$\dagger$ Key Laboratory of Advanced Materials of Tropical Island Resources, Ministry of Education, School of Science, Hainan University, Haikou 570228, China.

$\S$ Hainan Policy and Industrial Research Institute of Low-Carbon Economy, Hainan University, Haikou, 570228, PR China. 


\section{CONTENTS}

Table S1 Crystallographic data of HNU-34.

Table S2. LOD and $\mathrm{K}_{\mathrm{sv}}$ for TNP for HNU-34 and other materials.

Table S3. LOD and $\mathrm{K}_{\mathrm{sv}}$ for DNP for $\mathbf{H N U - 3 4}$ and other materials.

Figure S1. PXRD pattern of HNU-34.

Figure S2. TGA plot of HNU-34.

Figure S3. Excitation spectrum and the emission spectra of HNU-34.

Figure S4. Stern-Volmer plot of HNU-34 for TNP.

Figure S5. Stern-Volmer plot of HNU-34 for 2,4-DNP and 2,6-DNP.

Figure S6. Stern-Volmer plot of HNU-34 for 3-NP, 2-NP and 4-NP.

Figure S7. Recyclability test of HNU-34 for 2,4-DNP, 2,6-DNP and TNP.

Figure S8. Recyclability test of HNU-34 for 2-NP, 3-NP and 4-NP. 
Table S1. Crystal Data and Refinement Parameters for HNU-34.

\begin{tabular}{|c|c|}
\hline Identification code & HNU-34 \\
\hline Chemical formula & $\mathrm{C}_{21} \mathrm{H}_{28} \mathrm{~N}_{6} \mathrm{O}_{6} \mathrm{Zn}$ \\
\hline Formula weight & 541.85 \\
\hline Crystal Colour & pale-yellow \\
\hline Temperature (K) & $150(2)$ \\
\hline Crystal System & orthorhombic \\
\hline Space Group & Pccn \\
\hline$a(\AA)$ & $18.900(4)$ \\
\hline$b(\AA)$ & $24.784(5)$ \\
\hline$c(\AA)$ & $10.058(2)$ \\
\hline$\alpha\left(^{\circ}\right)$ & 90.00 \\
\hline$\beta\left(\left(^{\circ}\right)\right.$ & 90.00 \\
\hline$\gamma\left({ }^{\circ}\right)$ & 90.00 \\
\hline$Z$ & 8 \\
\hline$V\left(\AA^{3}\right)$ & $4711.0(16)$ \\
\hline D calc $\left(\mathrm{g} \mathrm{cm}^{-3}\right)$ & 1.426 \\
\hline $\mathrm{F}(000)$ & 2096.0 \\
\hline $\mathrm{Mu}\left(\mathrm{mm}^{-1}\right)$ & 1.086 \\
\hline $\mathrm{R}$ (int) & 0.0548 \\
\hline Number of parameters & 314 \\
\hline GOF on $\mathrm{F}^{2}$ & 1.017 \\
\hline$R_{1}^{\mathrm{a}}[\mathrm{I}>2 \delta(\mathrm{I})]$ & 0.0363 \\
\hline$w R_{2}{ }^{\mathrm{b}}($ all data $)$ & 0.0977 \\
\hline \multicolumn{2}{|c|}{${ }^{\mathrm{a}} \mathrm{R}_{1}=\sum|| \mathrm{F}_{\mathrm{o}}|-| \mathrm{F}_{\mathrm{c}} \| / \sum\left|\mathrm{F}_{\mathrm{o}}\right| \cdot{ }^{\mathrm{b}} \mathrm{wR}_{2}=\left\{\sum\left[\mathrm{w}\left(\mathrm{F}_{\mathrm{o}}{ }^{2}-\mathrm{F}_{\mathrm{c}}{ }^{2}\right)^{2}\right] / \sum\left[\mathrm{w}\left(\mathrm{F}_{\mathrm{o}}{ }^{2}\right)^{2}\right]\right\}^{1 / 2}$} \\
\hline
\end{tabular}


Table S2. Selected LOD and $\mathrm{K}_{\mathrm{sv}}$ for TNP for HNU-34 and other materials.

\begin{tabular}{|c|c|c|c|c|}
\hline Material & Detection & LOD & $K_{\text {sv }}\left(M^{-1}\right)$ & Ref. \\
\hline $\begin{array}{c}{\left[\mathrm{Zn}_{2}\left(\mathrm{H}_{2} \mathrm{~L}\right)_{2}(\mathrm{Bpy})_{2}\left(\mathrm{H}_{2} \mathrm{O}\right)_{3}\right.} \\
\left.\mathrm{H}_{2} \mathrm{O}\right]\end{array}$ & TNP & $0.49 \mu \mathrm{M}$ & $1.36 \times 10^{4}$ & $\mathrm{~S} 1$ \\
\hline $\begin{array}{c}{\left[\left(\mathrm{Zn}_{4} \mathrm{~L}_{2}\right)\left(\mu_{3}-\mathrm{OH}\right)_{2}\right]\left(\mathrm{NO}_{3}\right)_{2} \cdot} \\
0.5 \mathrm{H}_{2} \mathrm{O}\end{array}$ & TNP & $8.89 \mathrm{nM}$ & $8.49 \times 10^{4}$ & $\mathrm{~S} 2$ \\
\hline $\begin{array}{c}\left\{\left[\mathrm{Co}_{2}\left(\mathrm{Py}_{2} \mathrm{TTz}\right)_{2}(\mathrm{BDC})_{2}\right] \cdot 2\right. \\
\left.(\mathrm{DMF}) \cdot 0.5\left(\mathrm{H}_{2} \mathrm{O}\right)\right\} \mathrm{n}\end{array}$ & TNP & $0.90 \mu \mathrm{M}$ & $4.063 \times 10^{4}$ & S3 \\
\hline $\begin{array}{c}{\left[\mathrm{Zn}_{8}(\text { adenine })_{4}\left(\mathrm{~L}_{3}\right)_{6} \mathrm{O} \cdot 2 \mathrm{Me}\right.} \\
\left.{ }_{2} \mathrm{NH}_{2}\right] \cdot \mathrm{G}\end{array}$ & TNP & $12.9 \mathrm{nM}$ & $4.6 \times 10^{4}$ & S4 \\
\hline $\begin{array}{c}{\left[\mathrm{Zn}_{4}(\mathrm{DMF})(\text { urotropine })_{2}(\mathrm{~L}\right.} \\
\left.\left.4_{4}\right)_{4}\right]\end{array}$ & TNP & $7.1 \mu \mathrm{M}$ & $1.083 \times 10^{5}$ & S5 \\
\hline $\begin{array}{c}{\left[\left(\mathrm{CH}_{3}\right)_{2} \mathrm{NH}_{2}\right]_{3}\left[\mathrm{Zn}_{4} \mathrm{Na}\left(\mathrm{L}_{8}\right)_{3}\right]} \\
\cdot 4 \mathrm{CH}_{3} \mathrm{OH} \cdot 2 \mathrm{DMF}\end{array}$ & TNP & $5 \mu \mathrm{M}$ & $3.2 \times 10^{4}$ & S6 \\
\hline$\left\{\left[\mathrm{Zn}(\mathrm{IPA})\left(\mathrm{L}_{14}\right)\right]\right\}_{\mathrm{n}}$ & TNP & $0.12 \mu \mathrm{M}$ & $1.16 \times 10^{4}$ & S7 \\
\hline$\left[\mathrm{Zn}_{2}\left(\mathrm{NH}_{2} \mathrm{BDC}\right)_{2}\left(\mathrm{~L}_{15}\right)\right]_{\mathrm{n}}$ & TNP & $1.31 \mu \mathrm{M}$ & $7.3 \times 10^{4}$ & S8 \\
\hline HNU-34 & TNP & $36.15 \mathrm{nM}$ & $3.058 \times 10^{4}$ & This work \\
\hline
\end{tabular}


Table S3. Selected LOD and $\mathrm{K}_{\mathrm{sv}}$ for DNP for HNU-34 and other materials.

\begin{tabular}{ccccc}
\hline Material & Detection & LOD & $\mathbf{K}_{\mathbf{s v}}\left(\mathbf{M}^{-\mathbf{1}}\right)$ & Ref. \\
\hline$[\mathrm{Cd}(\mathrm{ppvppa})(1,4-\mathrm{NDC})]_{\mathrm{n}}$ & $2,4-\mathrm{DNP}$ & $70 \mathrm{ppm}$ & 118 & $\mathrm{~S} 9$ \\
$\left\{\left(\mathrm{NH}_{2}\left(\mathrm{CH}_{3}\right)_{2}\right)\left[\mathrm{Zn}_{4}(\mathrm{ddn})_{2}\right.\right.$ & $2,4-\mathrm{DNP}$ & $1.12 \mathrm{ppm}$ & $8.93 \times 10^{3}$ & $\mathrm{~S} 10$ \\
$\left.(\mathrm{COO})\left(\mathrm{H}_{2} \mathrm{O}\right)_{4}\right] \cdot$ solvent $_{\mathrm{n}}$ & & & & \\
& & & & $\mathrm{S} 11$ \\
{$\left[\mathrm{Cd}_{3}(\mathrm{BPPA})_{3}(\mathrm{aba})_{3}\right]_{\mathrm{n}}$} & $2,4-\mathrm{DNP}$ & no mention & $7.42 \times 10^{3}$ & \\
& & & & \\
HNU-34 & $2,4-\mathrm{DNP}$ & $42.55 \mathrm{nM}$ & $2.598 \times 10^{4}$ & This work \\
& $2,6-\mathrm{DNP}$ & $29.45 \mathrm{nM}$ & $3.753 \times$ & \\
& & & $10^{4}$ & \\
\hline
\end{tabular}




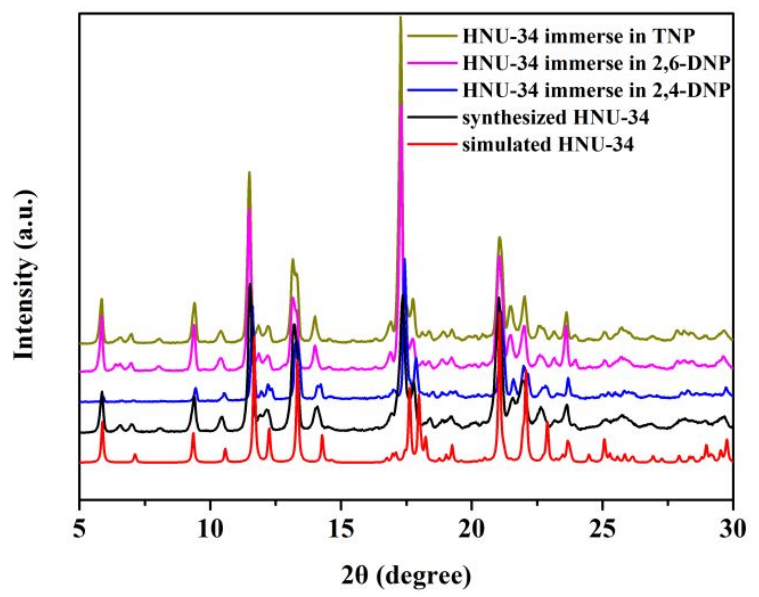

Figure S1. The PXRD patterns of HNU-34. 


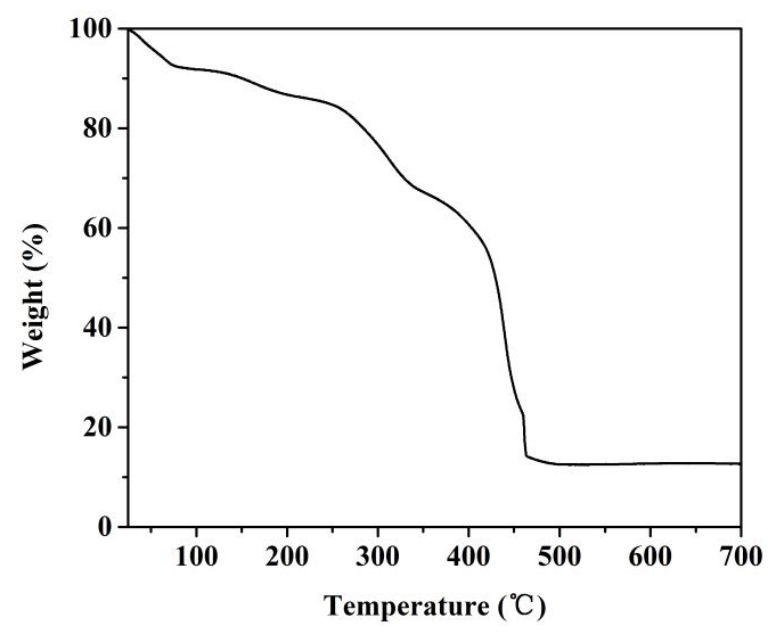

Figure S2. TG plot of HNU-34. 

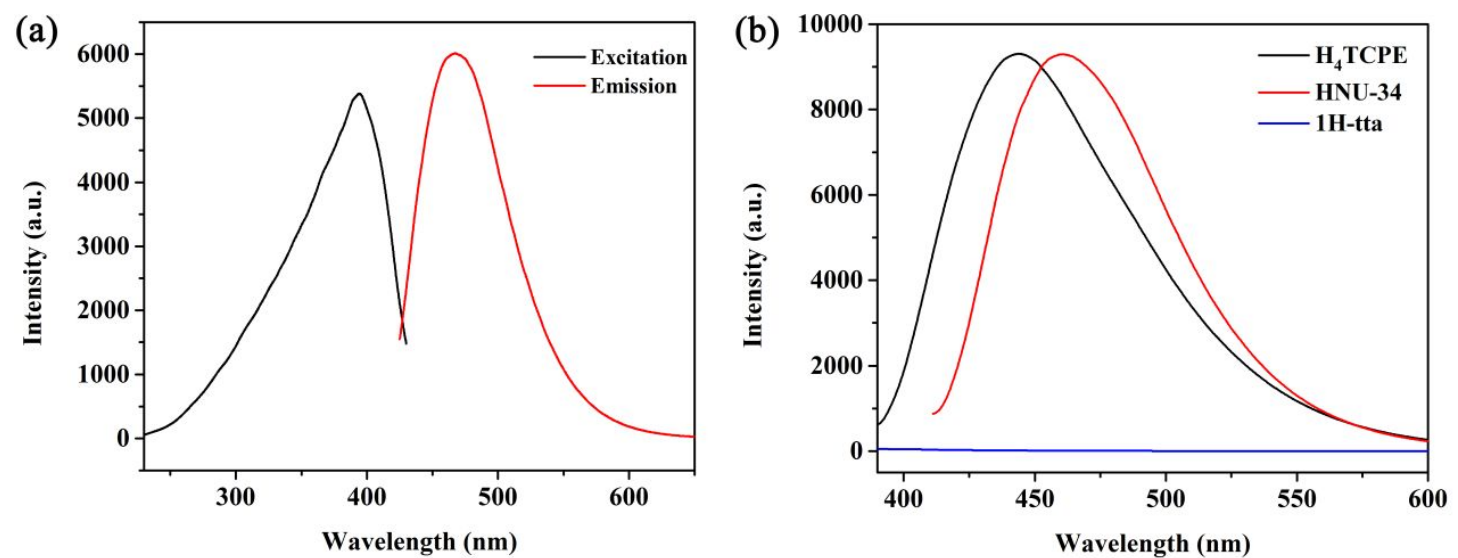

Figure S3. (a) Excitation and emission spectra of HNU-34. (b) Emission spectra for free $\mathrm{H}_{4}$ TPCE,1H-tta and HNU-34 $\left(\lambda_{\mathrm{ex}}=392 \mathrm{~nm}\right)$. 

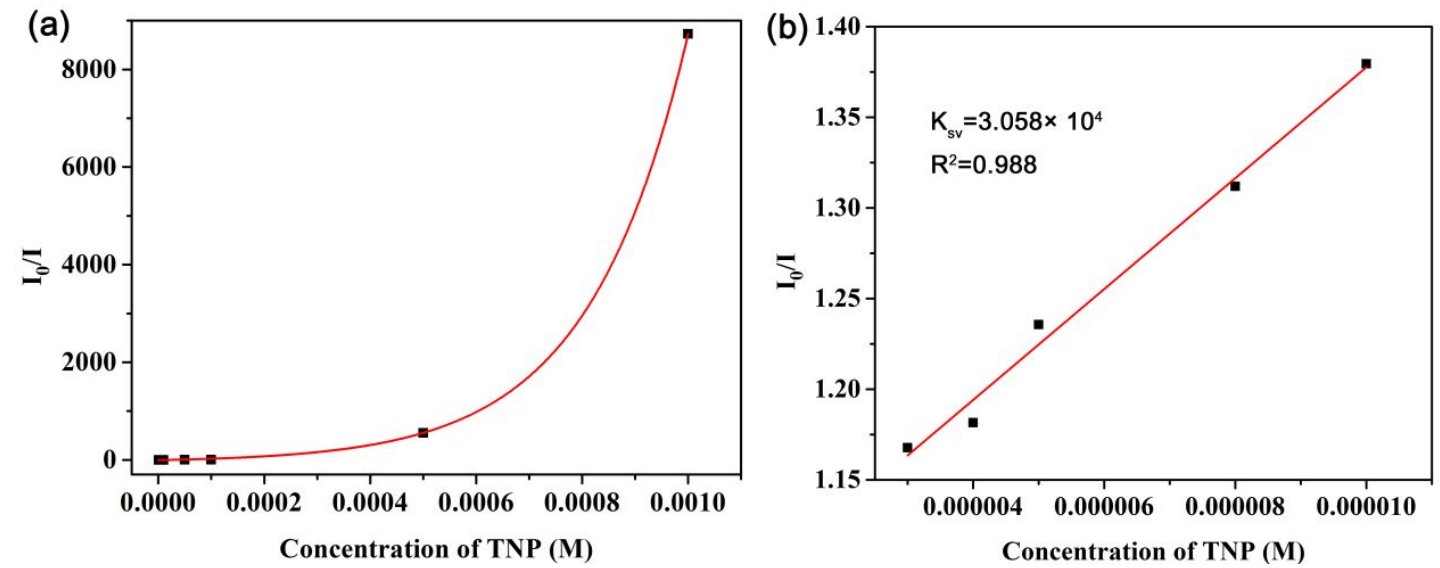

Figure S4. (a) Stern-Volmer plot of HNU-34 for TNP titration in DMF; (b) the dynamic quenching constant for TNP. 

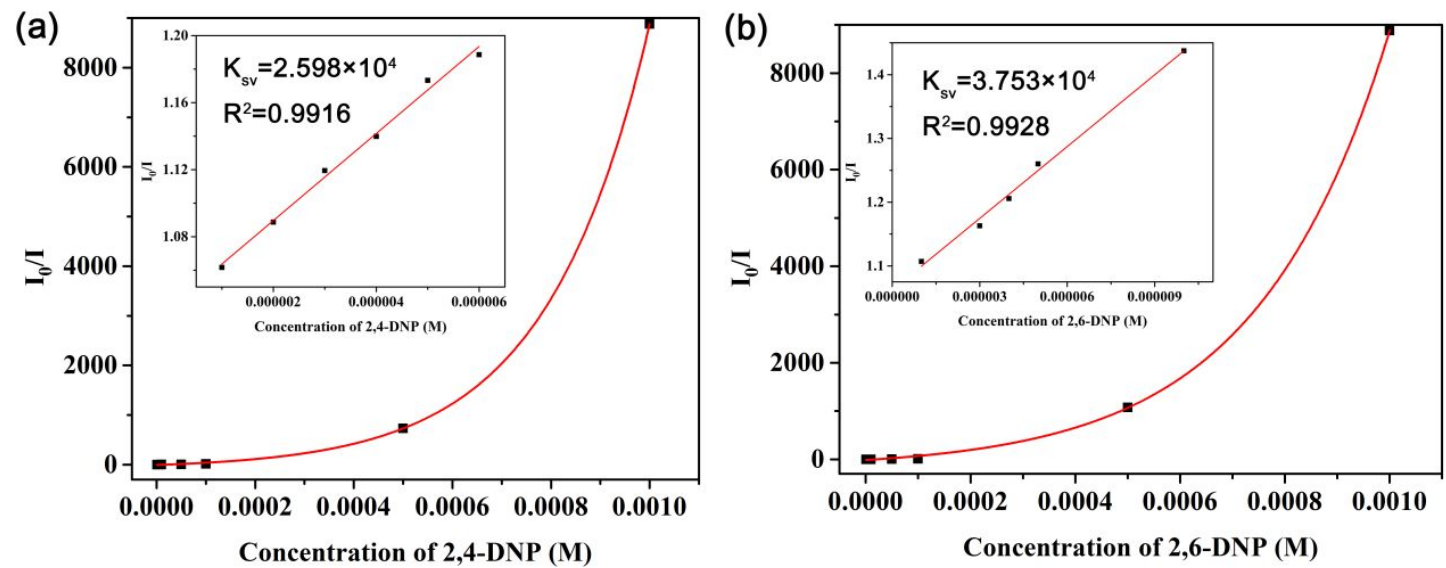

Figure S5. Stern-Volmer plot of HNU-34 for 2,4-DNP (a) and 2,6-DNP (b) titration in DMF. Insert: SV plot of HNU-34 with 2,4-DNP (a) and 2,6-DNP (b) at low concentrations. 

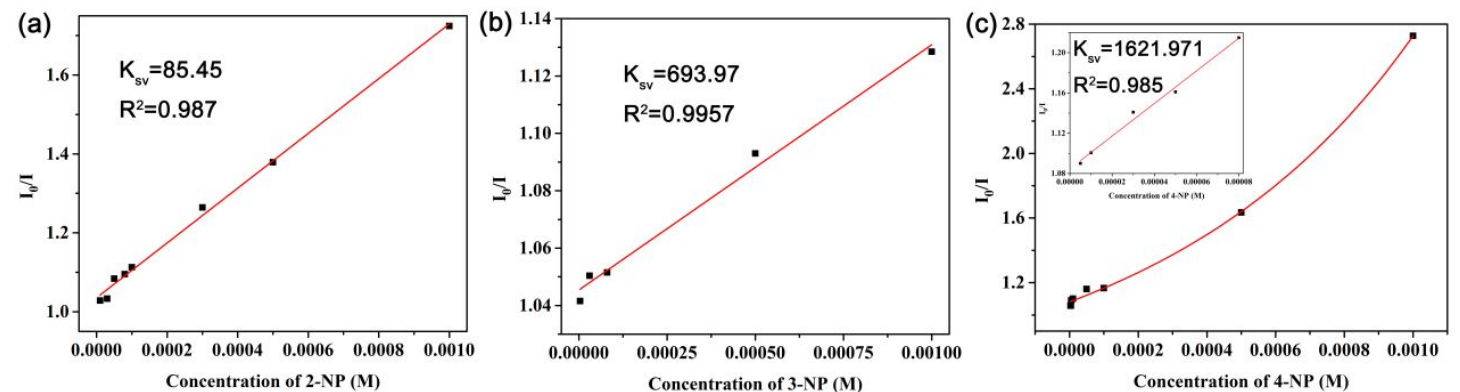

Figure S6. Stern-Volmer plot of HNU-34 for 3-NP (a), 2-NP (b) and 4-NP (c) titration in DMF. Insert: SV plot of HNU-34 with 4-NP (c) at low concentrations. 

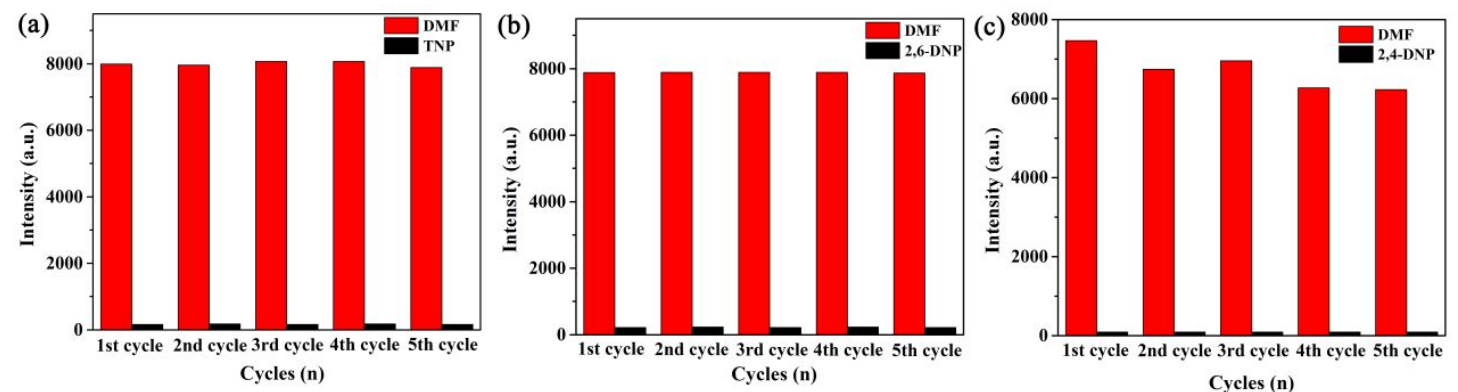

Figure S7. Recyclability experiments of HNU-34 in DMF. The red and black bars represent the fluorescence intensities of $\mathbf{H N U}-\mathbf{3 4}$ before and after the addition of TNP (a), 2,6-DNP (b) and 2,4-DNP (c) in each cycle, respectively. 

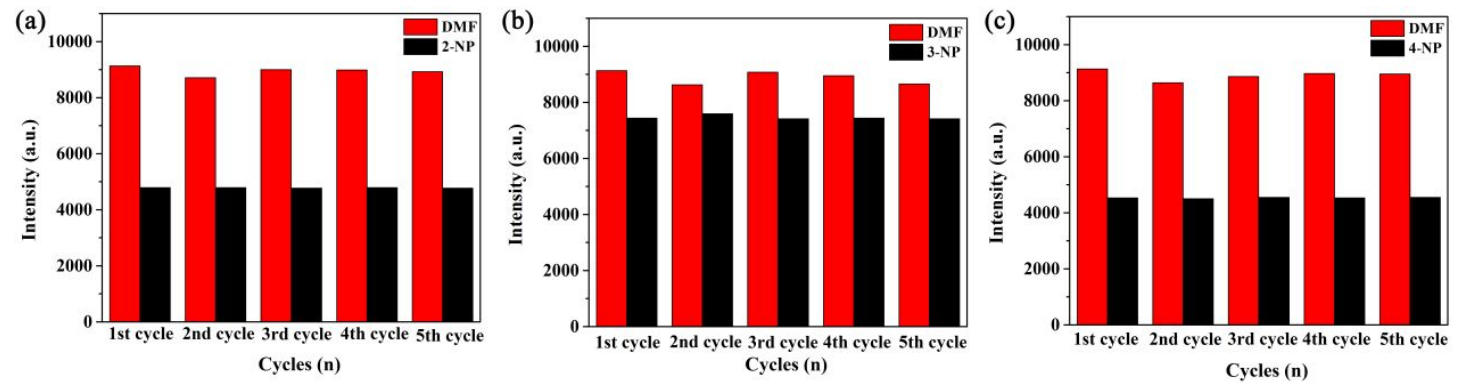

Figure S8. Recyclability experiments of HNU-34 in DMF. The red and black bars represent the fluorescence intensities of $\mathbf{H N U} \mathbf{3 4}$ before and after the addition of 2-NP (a), 3-NP (b) and 4-NP (c) in each cycle, respectively. 


\section{REFERENCES}

S1. Buragohain, A.; Yousufuddin, M.; Sarma, M.; Biswas, S., 3D Luminescent Amide Functionalized Cadmium Tetrazolate Framework for Selective Detection of 2,4,6-Trinitrophenol. Cryst. Growth Des. 2017, 17, 3170-3177.

S2. Ghosh, T. K.; Jana, S.; Ghosh, A., Exploitation of the Flexidentate Nature of a Ligand To Synthesize Zn(II) Complexes of Diverse Nuclearity and Their Use in Solid-State Naked Eye Detection and Aqueous Phase Sensing of 2,4,6-Trinitrophenol. Inorg. Chem. 2018, 57, 24, 15216-15228.

S3. Zhai, Z.; Yang, S.; Cao, M.; Li, L.; Du, C.; Zang, S., Rational Design of Three Two-Fold Interpenetrated Metal-Organic Frameworks: Luminescent Zn/Cd-Metal-Organic Frameworks for Detection of 2,4,6-Trinitrophenol and Nitrofurazone in the Aqueous Phase. Cryst. Growth Des. 2018, 18, $7173-7182$.

S4. Shanmugaraju, S.; Mukherjee, P. S., m-Electron rich small molecule sensors for the recognition of nitroaromatics. Chem. Commun. 2015, 51, $16014-16032$.

S5. Joarder, B.; Desai, A. V.; Samanta, P.; Mukherjee, S.; Ghosh, S. K., Selective and sensitive aqueous-phase detection of 2,4,6-trinitrophenol (TNP) by an amine-functionalized metal-organic framework. Chem. Eur. J. 2015, 21, 965-969.

S6. Zhou, E. L.; Huang, P.; Qin, C.; Shao, K. Z.; Su, Z. M., A stable luminescent anionic porous metal-organic framework for moderate adsorption 
of $\mathrm{CO}_{2}$ and selective detection of nitro explosives. J. Mater. Chem. A 2015, 3, 7224-7228.

S7. Parmar, B.; Rachuri, Y.; Bisht, K. K.; Laiya, R.; Suresh, E., Mechanochemical and Conventional Synthesis of $\mathrm{Zn}(\mathrm{II}) / \mathrm{Cd}(\mathrm{II})$ Luminescent Coordination Polymers: Dual Sensing Probe for Selective Detection of Chromate Anions and TNP in Aqueous Phase. Inorg. Chem. 2017, 56, 2627-2638.

S8. Dhankhar, S. S.; Sharma, N.; Kumar, S.; Kumar, T. J. D.; Nagaraja, C. M., Rational Design of a Bifunctional, Two-Fold Interpenetrated Znll-MetalOrganic Framework for Selective Adsorption of $\mathrm{CO}_{2}$ and Efficient Aqueous Phase Sensing of 2,4,6- Trinitrophenol. Chem. Eur. J. 2017, 23, 16204-16212.

S9. Mukherjee, S.; Desai, A. V.; Manna, B.; Inamdar, A. I.; Ghosh, S. K., Exploitation of Guest Accessible Aliphatic Amine Functionality of a MetalOrganic Framework for Selective Detection of 2,4,6-Trinitrophenol (TNP) in Water. Cryst. Growth Des. 2015, 15, 4627-4634.

S10. Ma, A.; Wu, J.; Han, Y.; Chen, F.; Li, B.; Cai, S.; Huang, H.; Singh, A.; Kumar, A.; Liu, J., Rational synthesis of luminescent uncommon $(3,4,6)$-c connected $\mathrm{Zn}(\mathrm{II})$ MOF: a dual channel sensor for the detection of nitroaromatics and ferric ion. Dalton Trans. 2018, 47, 9627-9633.

S11. Chen, M. M.; Zhou, X.; Li, H. X.; Yang, X. X.; Lang, J. P., Luminescent Two-Dimensional Coordination Polymer for Selective and Recyclable Sensing 
of Nitroaromatic Compounds with High Sensitivity in Water. Cryst. Growth Des. 2015, 15, 2753-2760. 